\title{
COMPARATIVE STUDY BETWEEN INTRAVITREAL VERSUS SUBTENON INJECTION OF TRIAMCINOLONE ACETONIDE IN MANAGEMENT OF DIABETIC MACULAR OEDEMA
}

\author{
Abd El-Rahman, M. ${ }^{(*)}$, Abd El-badie, M. \& Mohamed, A. \\ Ophthalmology dept., Faculty of Medicine, Al-Azhar Univ., Assiut, Egypt \\ *E-mail: mostafayoussef_eye@yahoo.com
}

\begin{abstract}
Purpose: To study the difference in the both safety and efficacy of Intravitreal (IVTA)versus subtenon (STTA ) triamcinolone acetonide injection as a treatment approach of diabetic macular edema (DME). Patients and Methods: 50 eyes of 38 diabetic patients diagnosed DME according to the ETDRS criteria were divided into two groups; each group consists of twenty five eyes. Group A were injected IVTA with $4 \mathrm{mg}(0.1 \mathrm{ml})$. Group B were injected STTA with 40 $\mathrm{mg}(1 \mathrm{ml})$. Results: In group Awe found that the mean central macular thickness (CMT) reduced from $465.6 u \pm 170.8 u$ at the baseline level to $285.9 u \pm 83.2 u, 267.5 u \pm 79 u$ and $288.4 u$ \pm 169 . 8 uat 1,3 and 6 months post injection respectively. In group $B$ we found that the mean CMT reduced from $327.65 u \pm 68.4 u$ at the baseline level to $273.2 u \pm 77.9,257.8 u \pm 83.6 u$ and $264.9 u \pm 104$.3uat 1.3 and 6 months post injection respectively. In group $A$ we found that the mean visual acuity (VA) was improved from 0.2 at the baseline to $0.4,0.3$ and 0.4 at 1,3 and 6 months post injection respectively. In group $B$ we found that the mean VA was improved from 0.3 at the baseline to $0.5,0.7$ and $0.7 a t 1.3$ and 6 months post injection respectively. In group $A$ we found that the mean intra ocular pressure (IOP) was changed from $16.2 \mathrm{mmHg} \pm 1.2 \mathrm{mmHg}$ at the baseline to $20.9 \mathrm{mmHg} \pm 6.9 \mathrm{mmHg}, 17.4 \mathrm{mmHg} \pm 1.6 \mathrm{~mm} \mathrm{Hg}$ and $17.4 \mathrm{mmHg} \pm 1.6 \mathrm{mmHg}$ at 1,3 and 6 months post injection respectively. In group $B$ we found that the mean IOP was changed from $15.15 \mathrm{mmHg} \pm 1.8 \mathrm{mmHg}$ at the baseline to15.6 $\mathrm{mmHg} \pm 1.8 \mathrm{mmHg}, 15.8 \mathrm{mmHg}$ $\pm 1.8 \mathrm{mmHg}$ and15.7 $\mathrm{mmHg} \pm 1.8 \mathrm{mmHg}$ at 1.3 and 6 months post injection respectively. Conclusion: STTA can achieve clinical results comparable to IVTA as regards the reduction of CMT and the improvement of VA although it achieves this effect somewhat slower.
\end{abstract}

Keywords: Diabetic macular edema, Intra vitreal triamcinolone acetonide injection, Subtenon triamcinolone acetonide injection

\section{Introduction}

The World Health Organization has estimated that people with diabetes are more than 180 million worldwide, with expectation of number elevation to the level of epidemic proportions during the upcoming 20 years [1]. Diabetic retinopathy (DR) is a known frequent diabetic complication. DR still a major health problem with significant socioeconomic implications, affecting approximately 50\% 
of diabetic subjects, and remains the leading cause of blindness among working populations of industrialized countries [2]. The risk factors of its occurrence and progression include duration of diabetes, genetic factors, glycemic control, nephropathy, hypertension, serum lipid level, anemia and pregnancy [3]. Diabetic macular edema (DME) is the most frequent sight threatening complication of DR, mainly in older patients with type 2 diabetes. It affects central vision even in the primary stages of retinopathy. Its role actually in the both processes of vision loss and retinal disease of diabetic patients is increasingly emerging. DME can lead to distortion of visual images and may result in a significant decline in visual acuity (VA) even without severe retinopathy [3]. Although macular edema is a known characteristic complication of DR that is related to the diabetic metabolic alterations, it does not necessarily fit the

\section{Patients and Methods}

This prospective study was performed in Ophthalmology dept. of Al-Azhar University Hospital-Assuit in the period between December 2014 and June 2015 and included 50 eyes of 38 diabetic patients diagnosed DME according to the ETDRS criteria. Approval of scientific committee of the Faculty of medicine, Al-Azhar university- Assuit, Egypt was obtained. A written informed consent was also obtained from each participant before the study. Inclusion criteria: Diagnosed DME according to the ETDRS criteria, Retinal thickness in the central macular area $>250$ microns by Time Domain OCT, media clarity, pupillary dilatation and patient cooperation sufficient for adequate fundus photographs and OCT. Exclusion criteria: Any macular edema due to a cause other than DM such as macular edema related to intraocular surgery, any ocular condition regular course of DR progression. Indeed, It may arise at any stage of DR, whether non proliferative, moderate, or severe, or even at the more advanced stages [4]. Fluoresce in angiography is used to distinguish and localize areas of focal versus diffuse leakage and it is helpful to exclude ischemic maculopathy [5]. Optical coherence tomography (OCT) is able to measure central macular thickness (CMT) and detect the type of macular edema whether cystoid, diffuse or tractional [6]. Intravitreal injection of corticosteroids (triamcinolone acetonide) (TA), constitutes a newer modality in DME therapy. However, this technique has certain distinct complications that have to be known prior to institution of therapy [7]. The aim of this work is to study the difference in the both safety and efficacy of intravitreal (IVTA) versus subtenon (STTA) triamcinolone acetonide

in which VA will not improve from resolution of macular edema, any ocular condition causing macular edema or altered VA before the study, history of prior treatment with intra vitreal, peribulbar, or retrobulbar corticosteroids for DME, history of focal/grid macular photocoagulation within 15 weeks prior to patient recruitment, history of PRP within 4 months prior to patient recruitment, history of prior vitrectomy or YAG capsulotomy performed within 2 months prior to randomization, Ocular or systemic infection. All patients were undergone Ophthalmological examination of the eye including ocular examination with slit lamp biomicroscopy, uncorrected visual acuity (UCVA), best corrected visual acuity (BCVA), intraocular pressure (IOP) measurements, detailed fundus examination, fundus fluoresce in angiography and OCT. The studied eyes were divided 
into 2 groups: the first group consists of 25 eyes of 18 diabetic patients, 10 males and 8 females, 16 type $2 \mathrm{DM}$ and 2 type $1 \mathrm{DM}$, were injected IVTA with $4 \mathrm{mg}(0.1 \mathrm{ml})$. Topical anesthesia at the ocular surface [Benoxinate $0.4 \%$ eye drop] followed by $5 \%$ povidone iodine drops at the conjunctival sac were used. Before injection, disinfection of the lashes, lids, and conjunctiva was performed using $10 \%$ povidone iodine. By 27-gauge needle, $4 \mathrm{mg}(0.1 \mathrm{ml})$ of TA (Kenacort-A) was slowly injected [4.0 mm inferotemporal to the limbus in phakic eyes]. A 27gauge needle was used to abolish clogging by suspended particles of corticosteroid. Special care was taken to inject TA into the central vitreous cavity, to prevent the dispersion of any suspended particles in front of the anterior hyaloid or posterior to the lens. Paracentesis was performed in selected cases owing to minimizing the risein IOP. Indirect ophthalmoscopy was utilized to confirm that suspension was localized properly intra vitreal and could perfuse the optic nerve head. The patients were advised to sleep in a head elevated position for 3 hours, so that the TA particles settle in the inferior vitreous and do not occlude the visual axis. A topical antibiotic therapy (ofloxacin) was applied 4 times for 7 days after the injection with anti glaucoma treatment in cases with increase of IOP. The second group consists of 25 eyes of 20 diabetic patients, 11 males and 9 females, 16 patients had type $2 \mathrm{DM}$ while 4 patients had type 1 DM were injected STTA with $40 \mathrm{mg}(1 \mathrm{ml})$. Topical anesthesia

\section{Statistical analysis}

Categorical data were delineated as number and percent $(\mathrm{N}, \%)$ while continuous data were existed as mean and standard deviation (Mean, SD). and eye disinfection were carried out similar to the first group. For subtenon TA injection $40 \mathrm{mg}$ of TA (Kenacort -A) were aspirated into a 27 gauge syringe. The needle was then replaced by a curved blunt metallic subtenon injection cannula having an arc length of $28 \mathrm{~mm}$. (NAGATA Subtenon injection cannula, 24 gauge/0.6mm. Geuder'-Heidelberg, Germany). The lower temporal bulbar conjunctiva was then exposed and a caliper was used to mark $8 \mathrm{~mm}$ from the limbus. A small buttonhole in the conjunctiva and Tenon capsule was created at the mark using Wesscot scissors to give access to the subtenon space. Blood vessels were avoided and minimal or no bleeding was encountered. The cannula was passed into the subtenon space with the aid of a conjunctival forceps to raise the conjunctiva and tenon capsule, and then directed backwards towards the macula till its hub and the drug was injected. Ballooning of the conjunctiva and tenon capsule was observed in all patients while extravasation of TA through the injection site was observed in some. After retracting the cannula irrigation and a micro sponge were used to remove any extravasated drug. The patient was given antibiotic eye drops for 7 days. A lubricant was also prescribed for patients with annoying postoperative pricking pain. Post operatively patients were scheduled for follow up at $2^{\text {nd }}$ day to evaluate serious adverse effect like endophthalmitis and IOP elevation. Then at $1^{\text {st }}$ week, $3^{\text {rd }}$ week, 1 month postoperatively then monthly till $6^{\text {th }}$ month after treatment.

Chi-square test and t-test were used to compare between categorical variables and continuous variables respectively. Continuous data were analyzed for 
normal distribution using Kolmogorov smirnov test and Q-Q Plots. A twotailed $p<0.05$ was considered statisti-

\section{Results}

The first group: 25 eyes of 18 diabetic patients were enrolled in this group. 10 of them $(55.50 \%)$ were males, while $8(44.50 \%)$ were females. Their ages ranged from 35 to 82 years (mean \pm SD): 60.33 years \pm 12.51 . They had diabetes for an average of 10.50 years +4.66 (mean $\pm \mathrm{SD}$ ). $88.88 \%$ (16/18) were with Type 2 DM while $11.12 \%(2 / 18)$ had type 1 DM.66.66 \% (12/18) were treated with cally significant. All analyses were performed with the SPSS 20.0 software.

oral hypoglyceamic drugs and $33.33 \%$ $(6 / 18)$ were treated with insulin. In addition to diabetes, $50 \%(9 / 18)$ of patients had hypertension less than 180/110.All of these patients had clinically significant macular edema (CSME) as mentioned by ETDRS, $38.88 \%(7 / 18)$ of them had CSME in both eyes, $27.77 \%(5 / 18)$ had CSME in his Rt eye only and $33.33 \%(6 / 18)$ in his Lt eye only, tab. (1).

Table (1) Demographics of baseline data in first group

\begin{tabular}{|l|c|c|c|}
\hline \multicolumn{1}{|c|}{ Variable } & No of pts & Percentage & Mean \pm SD (Range) \\
\hline Age [years] & $18 \mathrm{pt}$. & Ranging 35-82 ys. & 60.33 years \pm 12.51 \\
\hline Sex & $18 \mathrm{pt}$. & & \\
\hline Male & 10 & $55.50 \%$ & \\
\hline Female & 8 & $44.50 \%$ & \\
\hline DM & $18 \mathrm{pt}$. & & \\
\hline Type I DM & $2 / 18$ & $11.12 \%$ & \\
\hline Type II DM & $16 / 18$ & $88.88 \%$ & 10.50 years \pm 4.66 \\
\hline Duration [years] & & & \\
\hline On insulin & $6 / 18$ & $33.33 \%$ & \\
\hline On oral hypoglyceamic & $12 / 18$ & $66.66 \%$ & \\
\hline Hypertension & 9 & $50 \%$ & \\
\hline
\end{tabular}

Central macular thickness: the mean CMT reduced from $465.6 \mathrm{u} \pm$ $170.8 \mathrm{u}$ at the baseline level to $285.9 \mathrm{u}$ $\pm 83.2 \mathrm{u}, 267.5 \mathrm{u} \pm 79 \mathrm{u}$ and $288.4 \mathrm{u}$ $\pm 169.8 \mathrm{u}$ at 1,3 and 6 months of the follow up respectively, tab. (2) and fig. (1). Visual acuity: the mean VA was improved from 0.2 at the baseline to $0.4,0.3$ and 0.4 at 1.3 and 6 months post injection respectively, fig. (2). Intra ocular pressure: the mean IOP was changed from $16.2 \mathrm{mmHg} \pm 1.2$ $\mathrm{mmHg}$ at the baseline to $20.9 \mathrm{mmHg}$ $\pm 6.9 \mathrm{mmHg}, 17.4 \mathrm{mmHg} \pm 1.6 \mathrm{~mm} \mathrm{Hg}$ and $17.4 \mathrm{mmHg} \pm 1.6 \mathrm{mmHg}$ at 1.3 and 6 months post injection respecttively, fig. (3).

Table (2): Improvement of mean CMT of the first group over the follow up period

\begin{tabular}{|l|c|c|}
\hline & Mean Central macular thickness & Improvement \\
\hline Preoperative & $465.6 \mathrm{um} / \mathrm{SD} \pm 170.8 \mathrm{u}$ & \\
\hline Two weeks post injection & $358.9 \mathrm{um} / \mathrm{SD} \pm 85.2 \mathrm{u}$ & $19.9 \%$. \\
\hline One month post injection & $285.9 \mathrm{um} / \mathrm{SD} \pm 83.2 \mathrm{u}$ & $35.2 \%$ \\
\hline Three months post injection & $267.5 \mathrm{um} / \mathrm{SD} \pm 79 \mathrm{u}$ & $35.75 \%$ \\
\hline Six months post injection & $288.4 \mathrm{um} / \mathrm{SD} \pm 169.8 \mathrm{u}$ & $34.4 \%$ \\
\hline
\end{tabular}




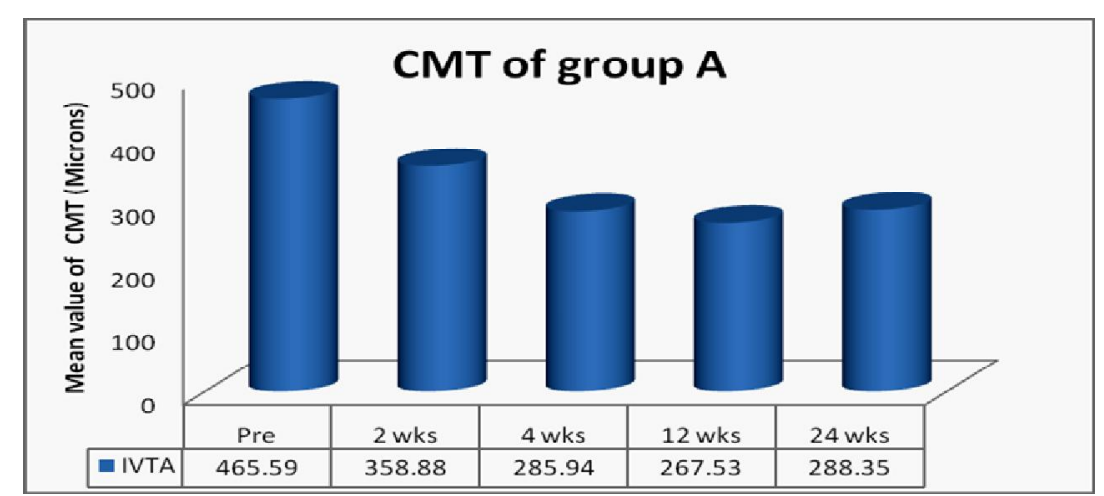

Figure (1) Shows changes in CMT of the triamcinolone acetonide Intravitreal injection group over the follow up period.

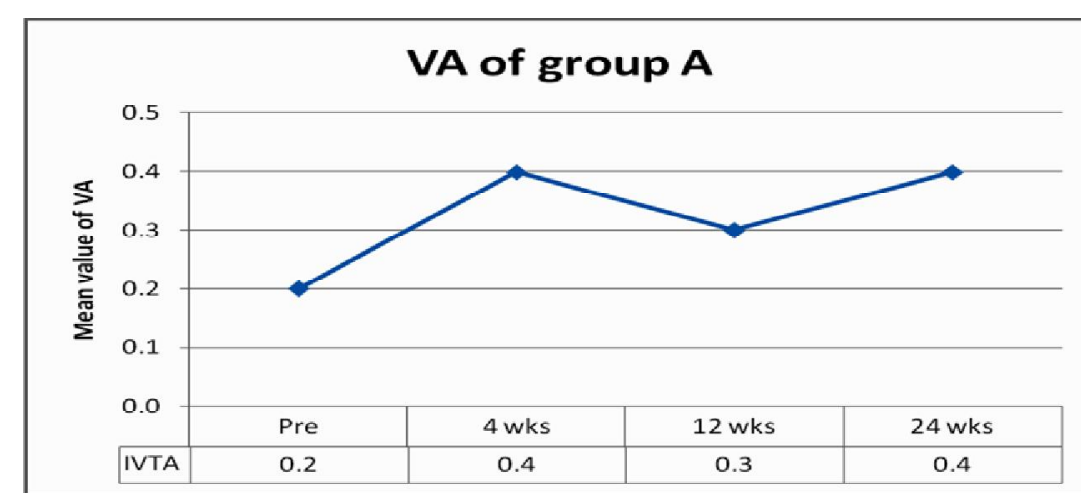

Figure (2) Shows improvement of visual acuity of the triamcinolone acetonide Intravitreal injection group over the follow up period.

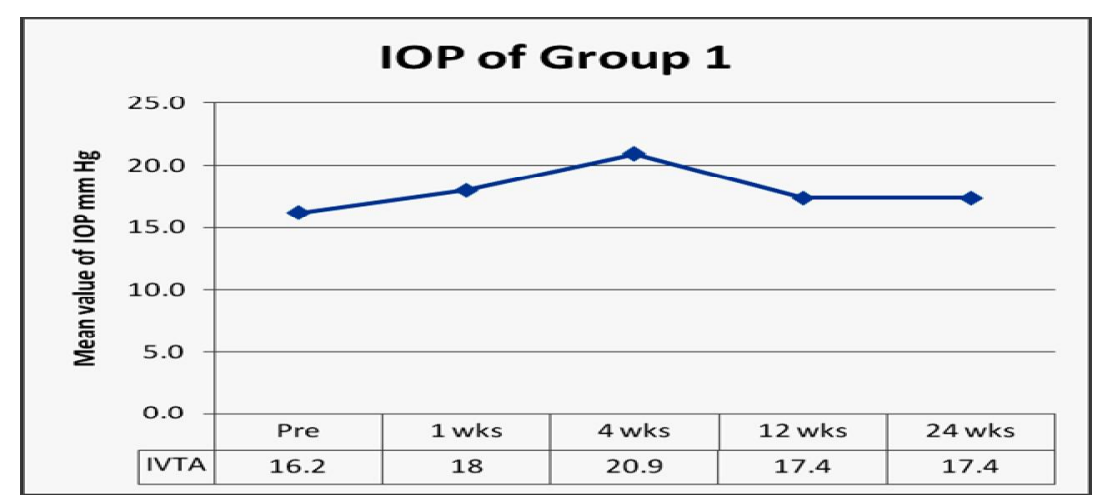

Figure (3) Shows changes in intra ocular pressure of the intra vitreal injection of triamcinolone acetonide group over the follow up period.

Complications: One patient suffered worsening of VA from $5 / 60$ pre injection to $2 / 60$ at 6 months after a transient improvement to 0.1 at 3 months. This was attributed to the recurrence of DME and nuclear cataract. Another patient suffered worsening of his VA from 0.5 pre injection to 0.2 at 6 months due to refractory DME. A third patient suffered a drop of VA from $6 / 60$ pre injection to $2 / 60$ at 6 months post injection, this was due to the developm- ent of subfoveal hard exudates and cataract. One patient suffered from endophthalmitis which manifested six days after the injection, he was treated with intravitreal antibiotics, his condition improved from $\mathrm{HM}$ to $\mathrm{CF} 80 \mathrm{~cm}$ at one month post injection he did not continue follow up. Three eyes had cataract after the injection, all in the form of nuclear cataract. Also four eyes suffered an increase in IOP at one month post injection. The second group: 25 eyes of 20 diabetic patients were included in 
this group. 11 of them $(55 \%)$ were males, while $9(45 \%)$ were females. Their ages ranged from 40 to 72 years (mean \pm SD) 61.55 years \pm 10.91 . They had diabetes for an average of 6.50 years $\pm 2.36 ; 80 \%(16 / 20)$ had Type 2 DM while 20\% (4/20) had type 1 DM. $50 \%(10 / 20)$ were treated with oral hypoglyceamic drugs and 50\%
$(10 / 20)$ were treated with insulin. In addition to diabetes, $30 \%(6 / 20)$ had hypertension. All of these patients had CSME as mentioned by ETDRS, $25 \%$ $(5 / 20)$ of them had CSME in both eyes , $40 \%(8 / 20)$ had CSME in his Rt eye only and $35 \%(7 / 20)$ in his Lt eye only, tab (3).

Table (3) Demographics of baseline data in second group

\begin{tabular}{|l|c|c|c|}
\hline \multicolumn{1}{|c|}{ Variable } & \multicolumn{3}{c|}{ The second group } \\
\hline Age [years] & No of pts & Percentage & Mean \pm SD (Range) \\
\hline Sex & $20 \mathrm{pt}$. & Ranging 40-72 ys. & 61.55 years \pm 10.91 \\
\hline Male & $20 \mathrm{pt}$. & & \\
\hline Female & 11 & $55.00 \%$ & \\
\hline DM & 9 & $45.00 \%$ & \\
\hline Type I DM & $20 \mathrm{pt}$. & & \\
\hline Type II DM & $4 / 20$ & $20 \%$ & \\
\hline Duration [years] & $16 / 20$ & $80 \%$ & \\
\hline On insulin & & & 6.50 years \pm 2.36 \\
\hline On oral hypoglyceamic. & $10 / 20$ & $50 \%$ & \\
\hline Hypertension & $6 / 20$ & $50 \%$ & \\
\hline
\end{tabular}

Central macular thickness: the mean CMT reduced from $327.65 \mathrm{u} \pm$ $68.4 \mathrm{u}$ at the baseline level to $273.2 \mathrm{u}$ $\pm 77.9,257.8 \mathrm{u} \pm 83.6 \mathrm{u}$ and $264.9 \mathrm{u}$ \pm 104.3 uat 1,3 and 6 months post injection respectively, tab (4) and fig. (4). Visual acuity: the mean VA was improved from0.3at the baseline to $0.5,0.7$ and 0.7 at 1.3 and 6 months post injection respectively, fig. (5). Intra ocular pressure: the mean IOP was changed from $15.15 \mathrm{mmHg} \pm 1.8$ $\mathrm{mmHg}$ at the baseline to15.6 $\mathrm{mmHg}$ $\pm 1.8 \mathrm{mmHg}, 15.8 \mathrm{mmHg} \pm 1.8 \mathrm{mmHg}$ and $15.7 \mathrm{mmHg} \pm 1.8 \mathrm{mmHg}$ at 1,3 and 6 months post injection respectively, fig. (6).

Table (4) Improvement of mean CMT of the second group over the follow up period

\begin{tabular}{|l|c|c|}
\hline Preoperative & Mean Central macular thickness & Improvement \\
\hline Two weeks post injection & $327.65 \mathrm{um} / \mathrm{SD} \pm 68.4 \mathrm{um}$ & \\
\hline One month post injection & $301.7 \mathrm{um} / \mathrm{SD} \pm 66.4 \mathrm{um}$ & $7.8 \%$ \\
\hline Three months post injection & $273.2 \mathrm{um} / \mathrm{SD} \pm 77.9 \mathrm{um}$ & $17 \%$ \\
\hline Six months post injection & $257.8 \mathrm{um} / \mathrm{SD} \pm 83.6 \mathrm{um}$ & $22 \%$ \\
\hline
\end{tabular}

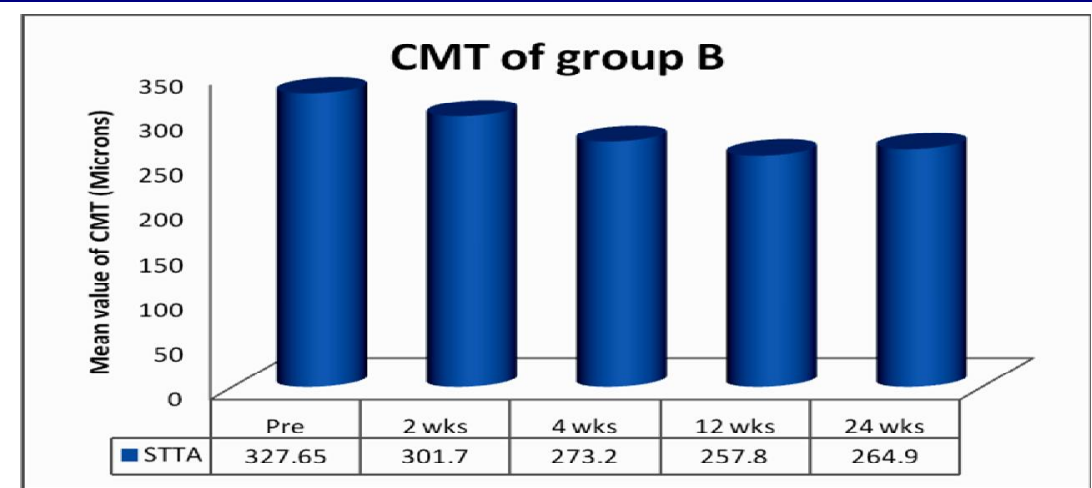

Figure (4) Shows changes in the CMT of the Sub-tenon's capsule TA injection group over the follow up period. 


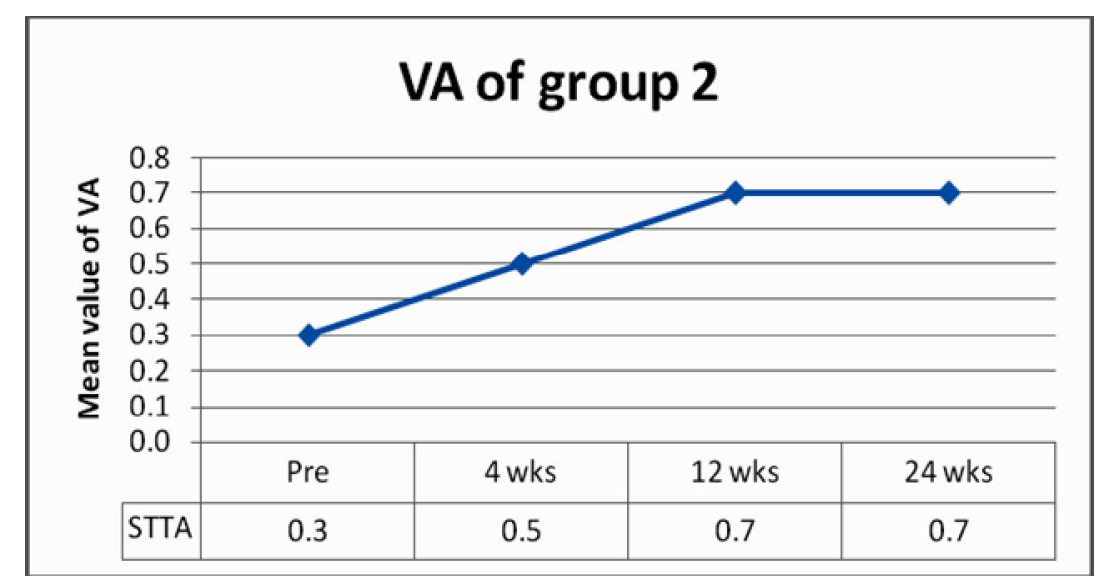

Figure (5) Shows improvement of visual acuity of the Sub-tenon's capsule TA injection group over the follow up period.

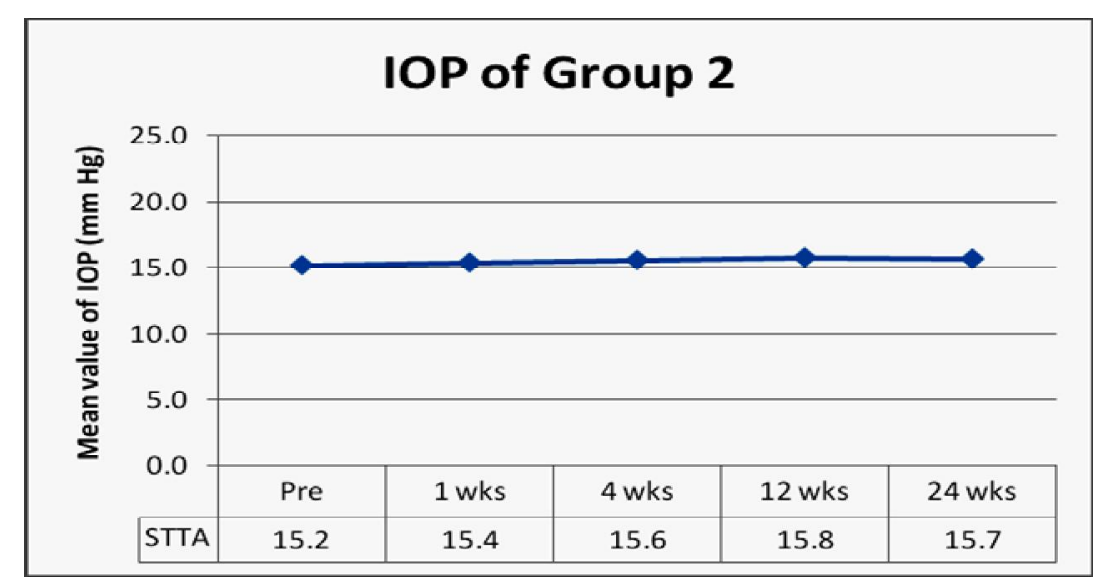

Figure (6) Shows changes in intra ocular pressure of the Sub-tenon's capsule TA injection group over the follow up period.

Complications: Five patients $(7$ eyes) suffered worsening of their VA by the end of the follow up period. These patients had persistent macular edema which did not improve after the injection, and progressed to form sub macular hard exudates which caused a dramatic drop of vision. None of the patients showed an increase in IOP after injection. No intraoperative complications were noted during the procedure, however reflux of the TA was noted in 3 patients (5 eyes) into the anterior subtenon space and through the button hole used to insert the cannula. No second injections were done for this group. Two eyes of 2 patients showed nuclear cataract at the 6 months follow up visit. Uneventful phacoemulsification was performed for both patients. No other complications were detected in this group. Comparison of the results of both groups: comparing the results of both groups showed that at 2 weeks post injection the CMT was significantly reduced in the IVTA group (107 um /19.9\%) more than the STTA group (26um $17.82 \%$ ) with a $\mathrm{p}$ value of 0.0057 . At one month the difference was 178.6 um $(35.2 \%)$ in the IVTA group and 54.5 um (17\%) in the STTA group ( $\mathrm{p}$ 0.0021). At 3 months the difference was 198.1 um (35.75\%) in the IVTA group and 69.85 um (22\%) in the STTA group ( $\mathrm{p}$ 0.0182). At 6 months the difference was 177.2 um (34.5) in the IVTA group and $62.75 \mathrm{um}$ $(19.72 \%)$ in the STTA group (p $0.0319)$, figs. $(7,8,9)$. 


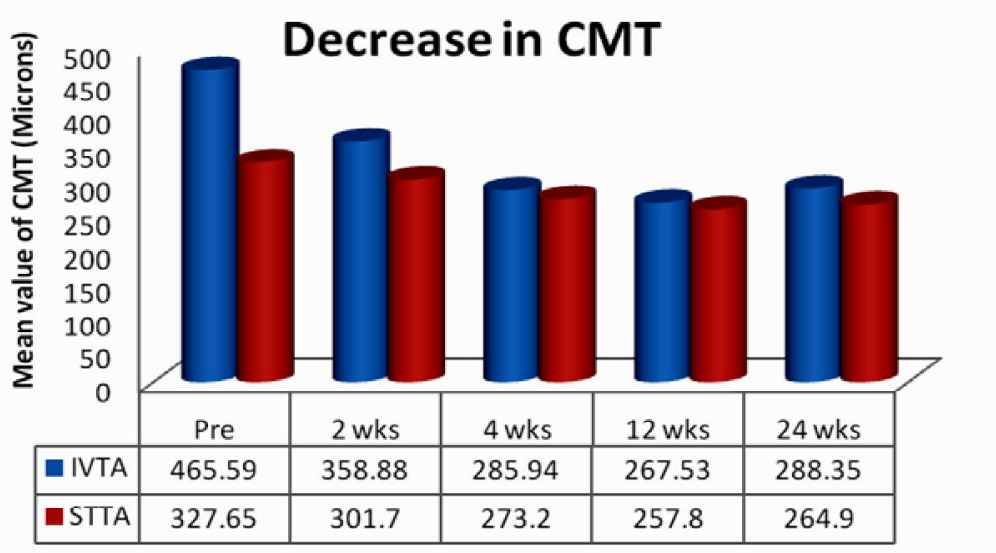

Figure (7) Shows chart comparing the changes in central macular thickness over the follow up period in absolute figures.

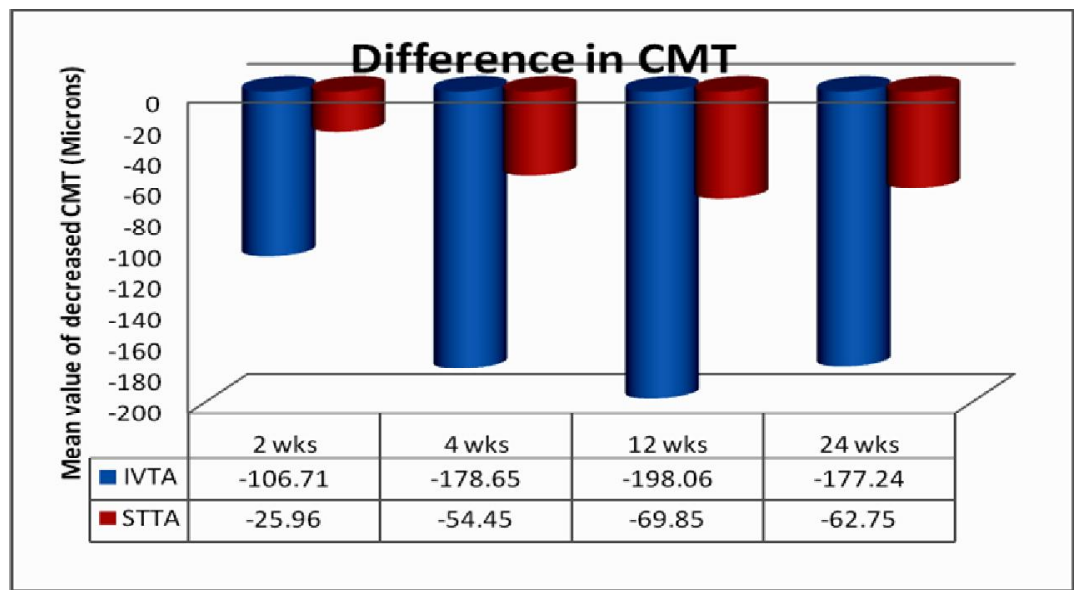

Figure (8) Shows chart comparing the decrease in central macular thickness over the follow up period in microns.

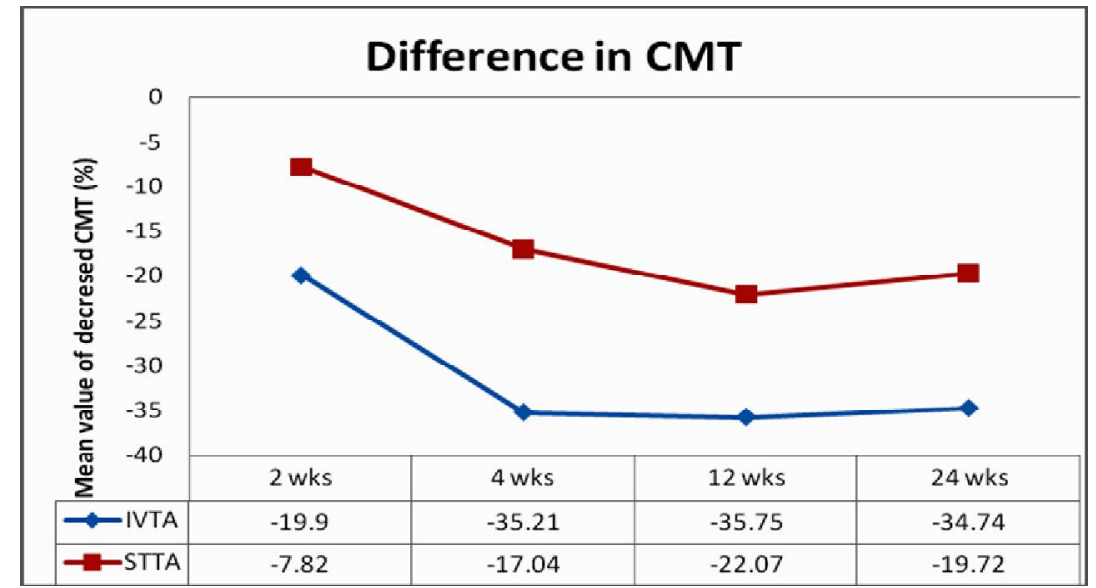

Figure (9) Shows chart comparing the decrease in central macular thickness over the follow up period in percentages.

Comparing the VA of the 2 groups; VA at 1month in the IVTA group improved from a baseline mean of 0.2 to 0.4 , gaining an improvement of 2 lines, with the STTA group improved from a baseline of 0.3 to 0.5 gaining an improvement of 2 lines ( $p$ 0.7216).
At 3 months the IVTA group was 0.3, with the STTA group improved to 0.7 gaining an improvement of 2 lines from baseline (p 0.0194).At 6 months the IVTA group was 0.4 , with the STTA group stable at 0.7 ( $p$ 0.1798), figs. $(10,11)$. 


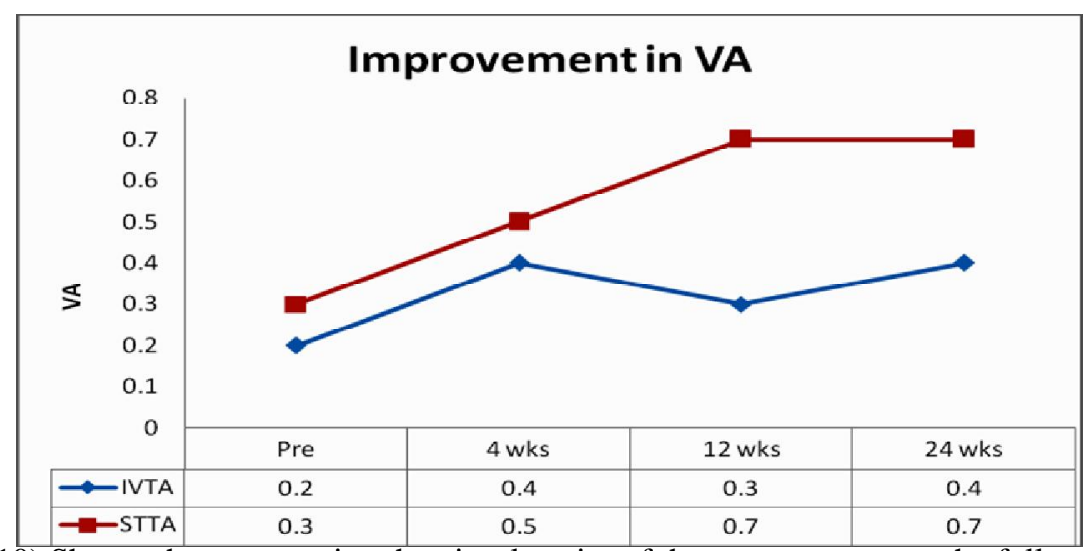

Figure (10) Shows chart comparing the visual acuity of the two groups over the follow up period.

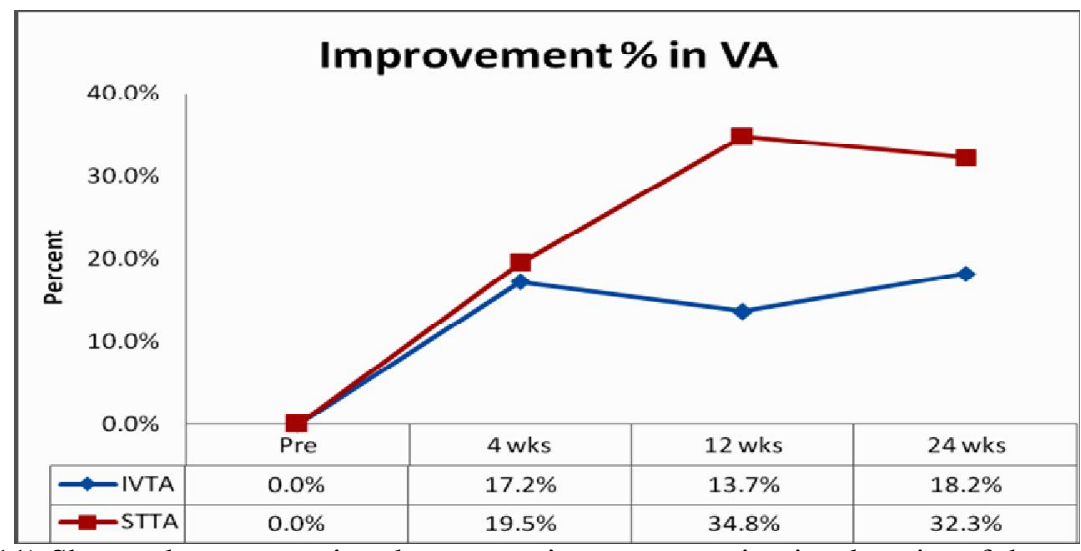

Figure (11) Shows chart comparing the percent improvement in visual acuity of the two groups.

Comparing the IOP of both groups; a rise in mean baseline IOP by 0.45 mmHg occurred in the STTA group at 4 weeks, while in the IVTA group there was a mean rise of $4.7 \mathrm{mmHg}$, with 4 eyes complicated by glaucoma ( $\mathrm{p} 0.0169$ ). At 3 months the difference in IOP from mean baseline was 1.18 and $0.65 \mathrm{mmHg}$ in the IVTA and STTA group respecttively ( $p$ 0.2201). At 6 months the difference in IOP from baseline was 1.24 and $0.55 \mathrm{mmHg}$ in the IVTA and STTA group respectively (p 0.1158), fig.
(12). The rate of occurrence of complications showed that the IVTA group had one case of endophthalmitis, 2 cases (4 eyes) of glaucoma and 3cases (3 eyes) of cataract. The STTA group had 2 cases ( 2 eyes) of cataract. The number of patients suffering from drop of VA from baseline at the end of the follow up period was higher in the STTA group (7 eyes) than the IVTA group (3 eyes not including the case of endophthalmitis).

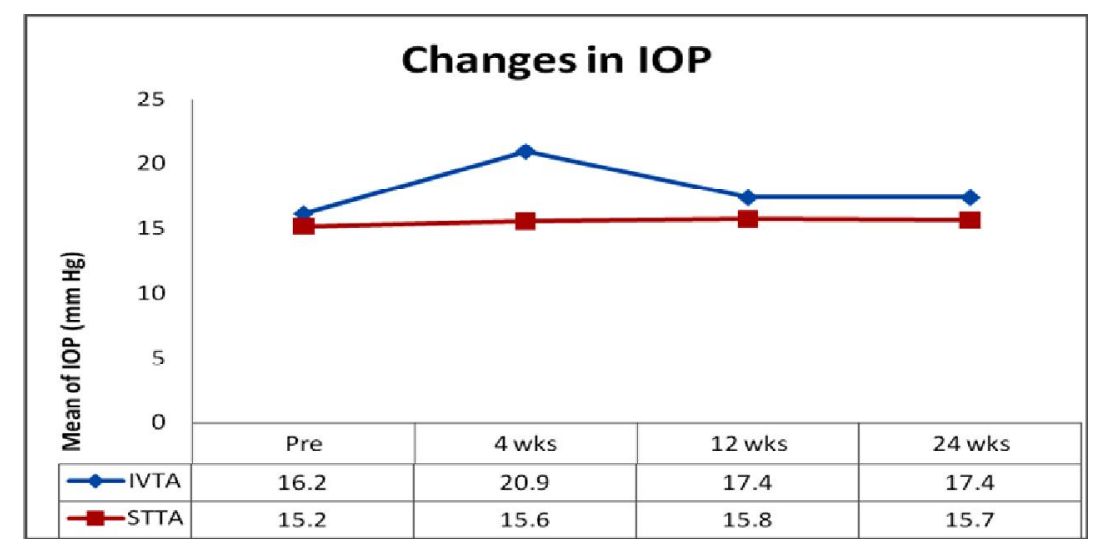

Figure (12) Shows chart comparing the intra ocular pressure of the two groups over the follow up period. 


\section{Discussion}

This study was conducted to study and compare the effectiveness and possible complication of intravitreal versus subtenon triamcinolone acetonide injection as a treatment approach of DME. From the current results, it is obvious that both techniques were able to reduce CMT despite the significant difference between them at 1, 3, 6 months post injection. IVTA showed more reduction of CMT than STTA. In the same point of view, Takata et al. conducted a study to compare the effectiveness of intravitreal injection (IVT) versus posterior subtenon infusion (STI) of triamcinolone acetonide performed during phacoemulsification cataract surgery in eyes with refractory diffuse diabetic macular edema and found that the central macular thickness reductions after surgery at all study follow-up visits were significantly greater in the IVTA group than in the STTA group. [8] In addition, the systematic review and meta-analysis study of Qi et al. showed that IVTA is more effective than is STTA in reducing CMT in patients with refractory DME within 3 months and the benefits of either regimen were no longer evident at 6 months [9]. Kaur et al. reported that intravitreal triamcinolone acetonide is more effective than posterior subtenon triamcinolone acetonide in reducing the CMT when used in DME [10]. However, the study of Soliman et al. showed that there was no significant difference between both techniques at 1 and 3 months as regards their posttreatment outcome for macular thickness [11]. In addition, Lotfy reported that both IVTA and STTA were able to equally reduce the retinal thickness [12]. Luo et al. also observed a none significant difference between the both different routes of Triamcinolone injection regarding CMT reduction at 2, 4,8,12 weeks [13]. Elfassi et al. also documented that both manoeuvers were able to significantly reduce central thickness with no significant difference between them [14].
Regarding Visual acuity, STTA achieved more improvement in VA at 3 months post injection. However both groups showed non-significant difference regarding improvement in VA at the end of follow up period. Actually, Ogura et al. delineated that the BCVA can be improved by STTA at 12 weeks [15]. Similar to the current results, Soliman et al. reported that the difference between IVTA and STTA in their post-treatment outcome for VA was not significant [11]. Also, Saleh et al. reported a none significant difference between both intravitreal and subtenon triamcinolone injection groups in the mean BCVA at 1,3 , and 6 months as well as change in BCVA from baseline [16]. El-Sayed et al. reported that both intravitreal and subtenon triamcinolone injections can significantly increase the visual acuity but the effect is early and more pronounced by the intravitreal injection [17]. In addition, the study of Luo et al. showed that the difference in VA improvement between both eyes received either intravitreal or subtenon triamcinolone injections was not statistically significant after 2, 4 and 8 weeks but was significantly better in subtenon group at 12 week [13]. When it comes to IOP, IVTA resulted in IOP elevation at first month of injection with 4 eyes complicated by glaucoma. This is in agreement with Soliman et al. who found that the change of IOP in the intravitreal injection group was greater than that of the posterior subtenon injection group [11]. Also, Qamar et al. observed a statistically significant rise in IOP in the eyes treated with an IVTA injection, whereas in the STTA injection group, no statistically significant variations in IOP were found [18]. Luo et al. noticed the significant elevation of IOP in eyes treated by IVTA at 12 weeks compared with eyes treated by STTA [13]. By the same way, Kaur et al. reported that intravitreal triamcinolone acetonide can produce more rise of IOP than 
posterior subtenon triamcinolone acetonide [10]. However, Soujanya et al. reported that IOP rise in IVTA group was not statistically significant; whereas, in the STTA group it became statistically significant [19].

\section{Conclusion}

STTA can achieve clinical results comparable to IVTA as regards the reduction in CMT and the improvement in VA although it achieves this effect somewhat slower.STTA carries a lower rate of intraocular complications than IVTA injection and does not appear to affect the $I O P$, thus making it suitable for glaucomatous patients. The effect of STTA decreases when the injection is associated with reflux of the drug through the button hole created for injection or to the anterior subtenon space.

\section{Acknowledgements}

We acknowledge all included participants, besides the clinical staff members of Ophthalmology Department, Al- Azhar University Hospital, Assuit, who helped the achievement of the study.

\section{References}

1.King, H., Aubert, R., Herman, W. Global burden of diabetes, 1995-2025: prevalence, numerical estimates, and projections. Diabetes Care. 1998; 21 (9): 1414-1431.

2.Aiello, L., Gardner, T., King, G., Blankenship, G., Cavallerano, J., Ferris, F., $3^{\text {rd }}$, Klein, R. Diabetic retinopathy. Technical review. Diabetes Care. 1998; 21: 143-156.

3.Singh, R., Ramasamy, K., Abraham, C., Gupta, V., Gupta, A. Diabetic retinopathy update. Indian J Opthalmol (2008); 56: 179-188.

4. Klein, B., Klein, R., Lee, K. Components of the metabolic syndrome and risk of cardiovascular disease and diabetes in beaver dam. Diabetes care (2002); 25 (10): 1790-1794.

5.Kylstra, J., Brown, J., Jaffe, G., Cox, T., Gallemore, R., Greven, C., Hall, J., Eifrig, D. The importance of fluorescein angiography in planning laser treatment of diabetic macular edema. Ophthalmology (1999); 106: 2068-2073.

6. Otani, T., Kishi, S. Patterns of diabetic macular edema with optical coherence tomography. $\boldsymbol{A m} \boldsymbol{J}$ Ophthalmol (1999); 127: 688-693.

7.Massin, P., Audren, F., Haouchine, B., Erginay, A., Bergmann, J., Benosman, R., Caulin, C., Gaudric, A. Intravitreal triamcinolone acetonide for diabetic diffuse macular edema. Ophthalmology (2004); 111 (2): 218-224.
8. Takata, C., Messias, A., Folgosa, M., Lucena, L., Lucena, D., Scott, I., Jorge, R. Intravitreal injection versus subtenon infusion of triamcinolone acetonide during cataract surgery in patients with refractory diabetic macular edema. Retina. 2010; 30 (4): 562-569.

9.Qi, H., Bi, S., Wei, S., Cui, H., Zhao, J. Intravitreal versus subtenon triamcinolone acetonide injection for diabetic macular edema: A systematic review and meta-analysis. Current Eye Research. (2012); 37 (12): 1136-1147.

10. Kaur, N., Singh, G., Singh, A., Singh, R., Dogra, S. Intravitreal versus posterior subtenon injection of triamcinolone acetonide in diabetic macular edema. Indian Journal of Clinical and Experimental Ophthalmology. (2016); 2(1):41-6.

11. Soliman, M., Hamed, A., Nehad, T., Metawee, I. Comparison between the effects of intravitreal and posterior subtenon injection of triamcinolone acetonide for treatment of diabetic macular edema. Benha Medical J. (2018); 35 (1): 13-19.

12. Lotfy, A. Subtenon triamcinolone acetonide versus Intravitreal triamcinolone acetonide for the treatment of diabetic cystoid macular edema. J Clin Exp Ophthalmol. (2016); 7(590):2.

13. Luo, D., Zhu, B., Zheng, Z., Zhou, H., Sun, X., Xu, X. Subtenon vs 
Intravitreal triamcinolone injection in diabetic macular edema, a prospective study in Chinese population. Pakistan J. of Medical Sciences. (2014); 30 (4): 749-754.

14. Elfassi, S., Hassanein, D., Riad, R., Hamza, H. Intravitreal versus posterior subtenon injection of triamcinolone acetonide in treatment of diabetic macular edema. Egyptian Retina Journal. (2017); 4 (2): 54-60.

15. Ogura, Y., Shimura, M., Iida, T., Sakamoto, T., Yoshimura, N., Yamada, M., Ishibashi, T. Phase II/III Clinical trial of sub-tenon injection of triamc-inolone acetonide (WP0508ST) for diabetic macular edema. Ophthalm-ologica. (2019); 241 (3): 161-169.

16. Saleh, M., Abdelmoneim, M., Fahmy, H., Riad, A., Lin, P. Posterior subtenon versus Intravitreal triamcinolone acetonide injection for the treatment of diabetic macular edema. $\boldsymbol{J}$. of
Current Medical Research and

Practice. (2017); 2 (2):141-149.

17. El-Sayed, S., Ellakwa, A., Badawy, N., El-Razik, A. Intravitreal versus subtenon injection of triamcinolone acetonide for diabetic macular edema. Menoufia Medical Journal. (2014); 27 (4): 636-642.

18. Qamar, R., Saleem, M., Saleem, M. Comparison of the efficacy between an intravitreal and a posterior subtenon injection of triamcinolone acetonide for the treatment of diffuse diabetic macular edema. The Eurasian Journal of Medicine. (2013); 45 (3): 185190.

19. Soujanya, P., Lodhi, S. Comparison of intravitreal triamcinolone and posterior subtenon triamcinolone in diffuse diabetic macular edema. Indian Journal of Clinical and Experimental Ophthalmology. (2018); 4 (1): 37-42. 